Original Contribution

\title{
AN ANALYSIS OF 212 CASES OF RIB FRACTURES DUE TO BLUNT THORACIC TRAUMA
}

\author{
Iv. Dimitrov*, Iv. Novakov, P. Bonev, A. Uchikov \\ Department of General and Thoracic Surgery, Medical University - Plovdiv, University Hospital \\ "St.George"- Plovdiv, Bulgaria
}

\begin{abstract}
PURPOSE. The aim of this retrospective study was to investigate the role of rib fractures for the outcome in blunt chest trauma, to examine the mortality rate and the need of hospitalization of patients underwent blunt thoracic trauma.

METHODS. 212 patients with fractured ribs after blunt thoracic trauma were included in the study. The mechanism of trauma, the number of fractured ribs; the type of associated thoracic injuries and the mortality rate were analyzed.

RESULTS. The patients were divided in two groups according to the number of fractured ribs-group 1patients with up to two fractured ribs- 72 patients/33,9\%/, and group 2- with three or more fractured ribs140 patients $/ 66,1 \% /$. The number of associated chest injuries was significantly higher in the second group- in 133 patients/95\%/.The mortality rate was 16,9\%/36 patients/.The mortality rate was significantly higher for the group of patients at the age above 65 years and for the group of patients with multiple $/ \geq 3 /$ rib fractures.

CONCLUSIONS. Our study confirms the role of rib fractures as a marker of severity in cases of blunt chest trauma patients.
\end{abstract}

Key words: blunt thoracic trauma, rib fracture, mortality, associated injuries

\section{INTRODUCTION}

Of all of the trauma-associated deaths, about $20 \%$ to $25 \%$ are due to thoracic traumas, which accounts for the third most common traumaassociated cause of death, after mortality from traumas of the head and extremities. Blunt thoracic traumas constitute the vast majority of thorax traumas, and the rib fractures are the most common finding (1-3). There are many studies that present a significant rate of rib fractures in patients underwent blunt thoracic trauma- from $7 \%$ to $40 \%(4,5)$. The fractures of ribs are mostly encountered in the elderly, and they are very rare in the pediatric population. The rib fractures are often overlooked and underestimated, especially in the presence of co-existing pathologies, which may result in increased morbidity and mortality. There are different studies which discuss the correlation between the ages, the number of fractured ribs, the presence of associated thoracic injuries and patient mortality and morbidity $(6,7)$. In our study,

\footnotetext{
* Correspondence to: Ivan N. Dimitrov

Medical University - Plovdiv; Department of Special Surgery; e-mail: indimitrov@abv.bg
}

we investigated the role of the fractured ribs as a marker of severity in cases of blunt chest trauma patients.

\section{MATERIAL AND METHODS}

We retrospectively evaluated the data of 212 patients with rib fracture due to blunt thoracic trauma, hospitalized and treated in the department of General and Thoracic Surgery at the University Hospital "St. George" for the period between January 2010 and December 2012. The patients were included basing on the results from the imaging studies (conventional chest X-ray and computed tomography of the chest). For each patient we defined the sex, the age, the mechanism of chest injury, the number of fractured ribs, the type and the severity of associated intrathoracic injuries, hospital stay and the results from treatment.

\section{RESULTS}

The mean age of the patients was 53,9 years (from 15- to 91-years old). According to the age, the patients were divided in two groupspatients under the age of 65 years and patients over 65 years of age. The number of patients from the first group was significantly higher- 
147 cases $(69,3 \%)$, the group of patients over 65 years included 65 patients $(20,7 \%)$. The male patients were 161 , and the female patients were 51. The analysis of the mechanism of trauma revealed that the leading cause for blunt chest trauma was the motor vehicle accident; the other factors are listed in Table 1. According to the number of fractured ribs, the patients were divided in two groups- group I included the patients with up to two fractured ribs (72 cases-33,9\%), and group II for the patients with multiple rib fractures( $\leq 3$ ribs)140 patients $(66,1 \%)$. We found associated thoracic injuries in 36 of the cases from group I. The number of associated chest injuries was significantly higher in group II- 133 cases
IV. DIMITROV, et al.

(95\%). The type of associated chest trauma is presented in Table 2. The mean hospital stay was 8,7 days. Death occurred in 36 patients with rib fractures $(16,9 \%)$, the lethality rate was higher for the group of patients over the age of 65years. The data revealed that the advanced age is a risk factor for mortality in patients underwent blunt chest trauma and rib fractures. Analyzing the correlation between the number of fractured ribs and the lethality rate, we found that the increasing number of fractured ribs lead to higher mortality rate Figure 1. The mortality rate was higher in patients with multiple fractured ribs- there was a positive correlation for the hole cohort, as for each of the groups divided by age.

Table 1. Mechanism of rib fractures, accordind the age distribution of the patients

\begin{tabular}{|lcccc|}
\hline \multicolumn{1}{|c}{$\begin{array}{c}\text { Mechanism of } \\
\text { trauma }\end{array}$} & $\begin{array}{c}\mathrm{N}=212 \\
(\%)\end{array}$ & $\begin{array}{c}\text { age } \leq 65 \\
(\%)\end{array}$ & $\begin{array}{c}\text { age }>65 \\
(\%)\end{array}$ & P \\
\hline 1.Motor vehicle accident & $121(57,1)$ & $94(63,9)$ & $27(41,5)$ & $<0,05$ \\
2. Pedestrian & $19(9,0)$ & $12(8,2)$ & $7(10,7)$ & - \\
3. Fall/Height/ & $42(19,8)$ & $27(18,4)$ & $15(23,1)$ & - \\
4. Fall/non-height/ & $13(6,1)$ & $1(0,7)$ & $12(18,5)$ & $<0,05$ \\
5. Other & $17(8,0)$ & $13(8,8)$ & $4(6,2)$ & - \\
\hline
\end{tabular}

Table 2. Associated chest injuries, according the type of rib fracture

\begin{tabular}{|lcccc|}
\hline Associated chest injuries & $\mathbf{N}$ & $\begin{array}{c}\geq \mathbf{2} \text { fractured } \\
\text { ribs }\end{array}$ & $\begin{array}{c}\text { Multiple } \\
\text { fractured } \\
\text { ribs( } \geq \mathbf{3} \text { ribs })\end{array}$ & $\mathbf{p}$ \\
\hline Pulmonary contusion & $\mathbf{1 3 9}$ & $\mathbf{1 5}$ & $\mathbf{1 2 4}$ & $<\mathbf{0 , 0 0 1}$ \\
Pulmonary lacerations & $\mathbf{3}$ & $\mathbf{0}$ & $\mathbf{3}$ & - \\
Pneumothorax & $\mathbf{4 0}$ & $\mathbf{1 0}$ & $\mathbf{3 0}$ & $<\mathbf{0 , 0 5}$ \\
Haemothorax & $\mathbf{4 5}$ & $\mathbf{5}$ & $\mathbf{4 0}$ & $<\mathbf{0 , 0 5}$ \\
Haemopneumothorax & $\mathbf{2 5}$ & $\mathbf{3}$ & $\mathbf{2 2}$ & $<\mathbf{0 , 0 5}$ \\
Fracture of clavicle & $\mathbf{1 1}$ & $\mathbf{1}$ & $\mathbf{1 0}$ & $<\mathbf{0 , 0 0 1}$ \\
Sternal fracture & $\mathbf{6}$ & $\mathbf{2}$ & $\mathbf{4}$ & $<\mathbf{0 , 0 5}$ \\
Scapula fracture & $\mathbf{5}$ & $\mathbf{0}$ & $\mathbf{5}$ & - \\
\hline
\end{tabular}

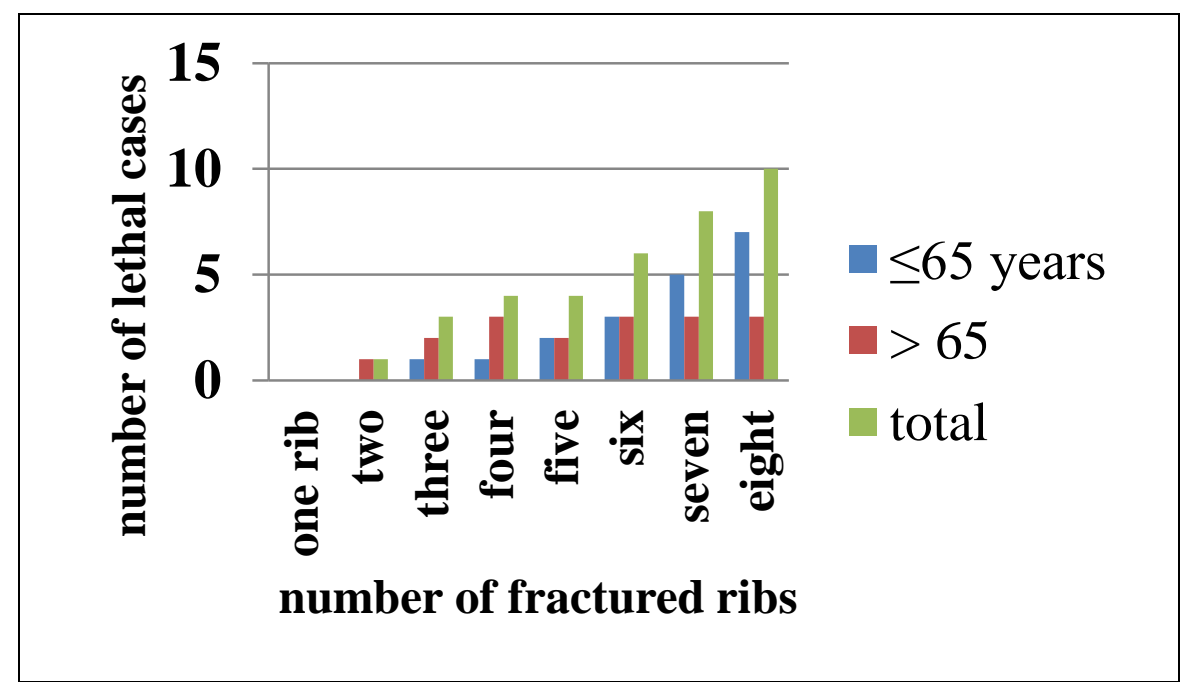

Figure 1. Lethality rate in patients with rib fractures, according to the number of fractured ribs and age distribution 


\section{DISCUSSION}

The rib fractures are the most common result of a blunt chest trauma. In different studies of patients with rib fractures, the fraction of male patients was $60 \%$ to $70 \%(8,9)$. In our study the male patients are predominant, which is compatible with the cited data. This could be explained with the physical activity and the higher rate of motor vehicle use.

Many studies have reported that as the number of fractured ribs increases, the mortality rate also increases. However, similar morbidity and mortality rates are reported in cases of isolated rib fractures. Lien (10) and Flagel (11) revealed a direct positive correlation between the number of fractured ribs and the morbidity and mortality rates. Ziegler (12) however did not find any correlation between the number of rib fractures and morbidity and mortality rates. In our study we found a significant difference for the mortality rate according to the number of fractured ribs. Basing on our data, we accept that the fracture of three or more ribs is an important risk factor for the patients underwent blunt chest trauma. Considering our findings, we recommend that all of the patients with fractured ribs should be hospitalized and carefully evaluated for associated intrathoracic injuries. There are various studies that reported a direct correlation between the age and the incidence of pulmonary complications and mortality in patients with rib fractures. The studies found that the age over 60years is a risk factor for higher mortality rate in patients underwent blunt chest trauma and rib fractures $(13,14)$. The positive correlation is explained with the particularities of patients in advanced age and in the elderly - the reduced pulmonary reserves, the increased sensitivity to the slightest hemodynamic changes, the presence of comorbidities. Nevertheless, the chest trauma should not be underestimated in the younger patients, especially when we take in mind that this is the group mostly affected by thoracic trauma. The pediatric and the young adult patients have a more elastic thoracic wall, therefore the lung parenchyma and the intrathoracic organs could be exposed to severe energy. In our study, we found that the age over 65 years is an important risk factor for mortality. The morbidity and the mortality rates are higher for the group of patients over 65 , even for the patients with isolated rib fractures. Taking in mind that it is a very vulnerable group, we recommend that all of these patients should be hospitalized and carefully evaluated.

\section{CONCLUSIONS}

IV. DIMITROV, et al.

This retrospective study presents the most common result of a blunt chest trauma- the rib fractures. Our study confirms the role of rib fractures as a marker of severity in cases of blunt chest trauma patients. The analysis of our results revealed that the mortality rate in patients underwent blunt chest trauma and rib fractures correlates directly with the number of fractured ribs and that the advanced age is a significant risk factor. Nevertheless, we recommend that all the patients with fractured ribs should receive thorough medical evaluation and follow-up.

\section{REFERENCES}

1. Dubinsky I, Low A. Non-lifethreateningblunt chest trauma: appropriate investigationand treatment. Am J Emerg Med; 15:240-243, 1997.

2. Inthorn $\mathrm{D}$, Huf $\mathrm{R}$. Thoracic trauma in multiple injured patients. Anast Intens Notfallmed:;27:498-5011992.

3. Yucel O, Sapmaz E, Caylak H, Gozubuyuk A.Hastaneyeyatirilmayigerektirentorakstrav mali 748 olgununanalizi. Gulhane Med J.;51:86-90, 2009.

4. Holcomb JB. Et al. Morbidity from Rib Fractures increases after age 45. J Am Coll Surg; 196: 549-555, 2003.

5. Brasel KJ. Et al. Rib fractures: Relationship with pneumonia and mortality. Crit Care Med 2006; 34:1642-1647.

6. Liman ST, Kuzucu A, Testepe AI, Ulasan GN, Topcu S. Chest injury due to blunt trauma. Eur J Cardiothorac Surg.; 23:3748, 2003.

7. Holcomb JB, McMullin NR, Kozar RA, Lygas MH, Moore FA. Morbidity from rib fractures increases after age 45. Journal of the American College of Surgeons.;196:549-55, 2003.

8. Sirmali M, Turut H, Topcu S, Gulhan E, Yazici U, Kaya S, et al. Acomprehensive analysis of traumatic rib fractures: morbidity, mortalityand management.

Eur J Cardiothorac Surg.;24:133-8, 2003.

9. Testerman GM. Adverse Outcomes in Younger Rib Fracture Patients.Southern Medical Journal. Volume 99, Number 4, April 2006.

10.Lien YC, Chen CH, Lin HC. Risk Factors for 24-Hour Mortality AfterTraumatic Rib Fractures Owing to Motor Vehicle Accidents: ANationwide Population-Based Study. Ann Thorac Surg.;88:1124, 2009.

11.Flagel BT. Half-a-dozen ribs: The breakpoint for mortality. Surgery; 138: 717$725,2005$. 
12.Ziegler D.W., Agarwal N.N. The morbidity and mortality of rib fractures. $J$ Trauma:;37:975-9, 1994.

13.Bulger EM, Arneson MA, Mock CN, Jurkovich GJ. Rib fracturesin the elderly. $J$ Trauma;48:1040-1046, 2000.
14.Palvanen M, Kannus P, Niemi S, Parkkari J, Vuori I. Epidemiology of minimal trauma rib fractures in the elderly. Calcif Tissue Int;62:274-277, 1998. 